\title{
Antioxidants, cholesterol, and ischaemic heart disease: CHAOS or confusion?
}

Cells in culture show very little uptake of normal low density lipoprotein (LDL), the main carrier of cholesterol in plasma. The missing link between cholesterol, LDL, and atheroma seemed to be revealed with the discovery that chemically modified LDL was taken up by cells in an uncontrolled manner via scavenger receptors, thus allowing overload. ${ }^{1}$ The key process was oxidation of fatty acid chains leading to modification of lysine residues in the receptor binding region of apolipoprotein B100. Similar effects could be produced by oxidative damage to LDL in vitro and supplementation with natural and artificial antioxidants seemed protective.

This intellectually intensely attractive explanation ${ }^{2}$ for the biological noise affecting relations between clinical atheroma and cholesterol, and the potential to explain the benefits of "natural" diets, was only briefly troubled by the difficulty in actually demonstrating any such modified LDL in the circulation. First, endothelial cells in culture were shown capable of inducing such changes, thus the key modifications may follow extravascular passage of LDL. Second, the necessary modifications to redirect uptake could be produced by very minor mistreatment of LDL in the laboratory-for example, by shaking in air in a test tube. The idea that such minimally modified LDL is the key component for atheroma advanced further with the demonstration that oxidised LDL can be cytotoxic, chemotactic, and growth stimulating, inducing migration and death of cells, and smooth muscle cell proliferation, in the putative developing lesion. ${ }^{3}$ Oxidised LDL has been demonstrated in human plaques, antibodies to oxidised LDL circulate in human plasma, ${ }^{4}$ and the transition elements iron and perhaps copper present in plaques could also promote the oxidative change. Variability could arise through levels of natural antioxidants. $\alpha$ tocopherol (vitamin $\mathrm{E}$ ) is the most abundant natural antioxidant in LDL, proposed as ideally positioned for a protective antioxidant and free radical scavenger, just below the surface of the LDL particle. Carotenoids (vitamin A) also enter the core of LDL, and ascorbate (vitamin $\mathrm{C}$ ) in the aqueous phase could perhaps offer surface protection or regeneration of tocopherols at the LDL particle surface. Red wine was promoted through its high content of antioxidant flavonoids, there is actually more in unfermented grape juice.

These associations have persuaded some $40 \%$ of the United States population to take vitamin supplements, mainly as antioxidants and sometimes at doses hugely in excess of those in natural diets, ${ }^{5}$ compromising both the ethics and practicality of placebo controlled studies. Happily, overt toxicity seems rare, but what about the benefits?

Three patterns of relation have been pursued: cellular laboratory studies of LDL including some with material from patients and volunteers; associations between reported intakes and measured levels of natural antioxidants, generally as $\alpha$ tocopherol, and outcome; and clinical studies of outcome after supplementation with exogenous specific agents. Laboratory studies have been generally supportive and have suggested wider aspects of atheroma in which antioxidants might be involved. Growth factor signalling processes underlying responses to oxidised LDL are being unravelled through in vitro and mainly animal experiments. $^{3}$ Vitamin $\mathrm{E}$ can maintain acetylcholine dependent endothelium derived vessel relaxation, possibly by protecting nitric oxide against free radical attack, and reducing the response to protein kinase $\mathrm{C}$ stimulation; thus any benefits of vitamin $\mathrm{E}$ and other antioxidants may also operate independently of LDL. ${ }^{6}$ But vitamin E half-lives in plasma are shorter than those for LDL, thus associations in plasma are relatively transient. Laboratory data on vitamin $\mathrm{E}$ concentrations has to be equalised for LDL concentration as LDL is the predominant carrier of vitamin $\mathrm{E}$ in plasma. ${ }^{7}$ Antibody titres to oxidised LDL are not associated with extent of clinical disease in all studies. In addition, high concentrations could be good or bad, flagging increased exposure to an atheromatous agent or its removal from plasma to clinical advantage. Observational clinical studies of reported intakes and measured levels of antioxidants do show some associations with below average expression of coronary artery disease, more clearly for vitamin $\mathrm{E}$, and where any reported supplements are taken for at least two years. ${ }^{8} 9$ Plasma levels of all natural antioxidants are higher in vegetarians, ${ }^{10}$ and fish oil unsaturates - which might enhance the potential of LDL for oxidative damage-seemed to enhance resistance, possibly because the fish oil preparations are supplemented with vitamin $\mathrm{E} .{ }^{11}$

These observations generally support the proposal that "natural" diets and in particular their antioxidants are good for you. However, clinical trials of direct supplementation have not met expectations. Probucol is a drug which can modestly lower cholesterol and high density lipoprotein (HDL), but it is also an extremely powerful antioxidant with effects beyond those of vitamin $\mathrm{E}$ and other natural agents. It has therefore been given to patients with dyslipoproteinaemia and severe atheromatous disease, improving lipid profiles but without any dramatic effects on progression. ${ }^{12}$ Most trials of supplementation have shown no definite effect: one large trial showed that supplementation with vitamin $E$ had little effect, and vitamin $A$ a negative effect, on the progression of angina. ${ }^{13}$ Concerns that vitamins $\mathrm{A}$ and $\mathrm{E}$ might in some way compete are not well supported. In the randomised trial of variable but in some cases extremely high doses of vitamin $\mathrm{E}$ in patients with coronary disease (CHAOS trial), ${ }^{14}$ no single cardiovascular outcome was improved and non-cardiac mortality actually increased. Cardiovascular events overall defined as death plus non-fatal infarction were significantly reduced, but from the events in the treated group, many patients had not benefitted from their supplementation. This situation is remarkably like that arising with cholesterol a few years ago, in that benefits were equivocal but more evident when trials were large and of several years duration, and that concerns arose over adverse effects. These concerns have been addressed by appropriate and appropriately powered clinical trials. Supplementation with pharmaceutical antioxidants may have a quite different balance of benefit and adverse effect than diets significantly enriched with foods containing antioxidants. But if such policy either through diet choice or enrichment was the nirvana for vascular disease as is widely claimed, then the benefits of current widespread change should now be clearly evident. It was interesting that at the American Heart Association meeting in 1996 the "smart money" was going on homocysteine, another very attractive idea based on persuasive association not direct proof, and locked in to the benefits of vitamins and natural foods.

Appropriate clinical trials have to be the arbiter of population action and at present the immensely attractive 
hypothesis that a shortage of natural antioxidants and perhaps other vitamins underpins human vascular disease is no more than that. All may be true but present evidence is not a sound basis for population action.

\section{A F WINDER}

Department of Chemical Pathology $\mathcal{E}$ Human Metabolism, Royal Free Hospital NHS Trust $\mathcal{E}$ School of Medicine, Pond Street, London NW3 2QG, United Kingdom email:tony_w@rfhsm.ac.uk

1 Steinberg D, Parthasarathy S, Carew TE, Khoo JC, Witztum JL. Beyond cholesterol: modifications of low-density lipoproteins that increase its atherogenicity. N Engl f Med 1989;320:915-24.

Witztum J. The oxidation hypothesis of atherosclerosis. Lancet 1994;344: 793-5.

3 Libby P. The molecular basis of the acute coronary syndromes. Circulation 1995;91:2844-850.

4 Antibodies to oxidised LDL in atherosclerosis [editorial]. Lancet 1992;339. 899-900.

5 Meyers DG, Maloley PA, Weeks D. Safety of antioxidant vitamins. Arch Intern Med 1996;156:925-35.

6 Keaney JF Jr, Gou Y, Cunningham D, Shwaery GT, Xu A, Vita JA. Vascular incorporation of alpha-tocopherol prevents endothelial dysfunction due to oxidised LDL by inhibiting protein kinase C stimulation. $\mathcal{f}$ Clin Invest 1996;98:386-94

7 Regnstrom J, Nilsson J, Moldeus P, Strom K, Bavenholm P, Tornvall P, et al. Inverse relation between the concentration of low-density-lipoprotein vita$\min \mathrm{E}$ and severity of coronary artery disease. Am $\mathcal{f}$ Clin Nutr 1996;63:377-85.

8 Stampfer MJ, Hennekens CH, Manson JE, Colditz GA, Rosner B, Willett WC. Vitamin $\mathrm{E}$ consumption and the risk of coronary disease in women. $N$ Engl f Med 1993;328:1444-9.

9 Rimm E, Stampfer MJ, Ascherio A, Giovannucci E, Colditz GA, Willett WC. Vitamin E consumption and the risk of coronary heart disease in men. $N$ Engl f Med 1993;328:1450-6.
10 Krajcovicova-Kudlakova M, Simoncic R, Babinska K, Bederova A, Brtkova A, Magalova T, et al. Selected vitamins and trace elements in blood of vegetarians. Ann Nutr Metabol 1995;39:334-9.

11 Panzetta O, Cominacini L Garbin U, Fratta Pasini A, Gammaro L, Bianco $\mathrm{F}$, et al. Increased susceptibility of LDL to in vitro oxidation in patients on $\mathrm{F}$, et al. Increased susceptibility of $\mathrm{LDL}$ to in vitro oxidation in patients on maintenence haemodialysis:

12 Kajinami K, Nishitsiji M, Takeda Y, Shimizu M, Koizumi J, Mabuch H. Long-term probucol treatment results in regression of xanthomas, but in progression of coronary atherosclerosis in a heterozygous patient with familial hypercholesterolaemia. Atherosclerosis 1996;120:181-7.

13 Rapola JM, Virtamo J, Haukka JK, Heinonen JP, Albanes D, Taylor PR, et al. Effect of vitamin $\mathrm{E}$ and beta carotene on the incidence of angina pectoris. A randomised double-blind, controlled trial. $\mathcal{F} A M A$ 1996;275:693-8.

14 Stevens NG, Parsons A, Schofield PM, Kelly F, Cheeseman K, Mitchinsom $\mathrm{MJ}$, et al. Randomised controlled trial of vitamin $\mathrm{E}$ in patients with coronary disease: Cambridge heart antioxidant study (CHAOS). Lancet 1996;347:781-6.

\section{Dr Mitchinson comments:}

I concede that those of us who have invested years of work in the lipid oxidation hypothesis might sometimes be over enthusiastic. I cannot, however, agree that ". . .no single cardiovascular outcome was improved..." in the CHAOS trial. Myocardial infarction diminished in those taking vitamin $\mathrm{E}$, to a degree seen with no other form of treatment. I have to agree that the benefits of vitamin $\mathrm{E}$ do not yet convince everyone, but I remain optimistic. Indeed, despite our areas of disagreement, the only real difference, it seems, is that my glass is half full and Professor Winder's half empty.

\section{Molecular Pathology_April 1997 contents}

\section{Reviews}

CD44 and the adhesion of neoplastic cells

Z Rudzki, S fothy

Pathogenic mechanisms of neuronal damage in the AIDS dementia complex

$S$ Swingler

\section{Papers}

Routine diagnosis of large granular lymphocytic leukaemia by Southern blot and polymerase chain reaction analysis of clonal $\mathrm{T}$ cell receptor gene rearrangements

\section{K Ryan, $H$ D Alexander, T C M Morris}

Expression of a novel mRNA in human head and neck squamous cell carcinoma cells

\section{f A Werner, $T$ Görögh, B $M$ Lippert, $S$ Gottschlich, K Heidorn, $B \mathcal{f}$ Folz, $H$ Rudert}

Fas ligand is not only expressed in immune privileged human organs but is also coexpressed with Fas in various epithelial tissues

\section{Xerri, E Devilard, $\mathcal{F}$ Hassoun, C Mawas, F Birg}

Interphase ribosomal RNA cistron silver staining in refractory anaemias with and without excess blasts

N N Namaer, G N Salogub, I B Nefedova

HHV8 and Kaposi's sarcoma: a time cohort study

$M M$ Kennedy, $S$ B Lucas, $R$ R fones, $D$ D Howells, $S \mathcal{F}$ Picton, $E$ E Hanks, $\mathcal{F}$ O’D McGee, $\mathcal{F} \mathcal{F}$ O'Leary

Absence of human papillomavirus genomic sequences detected by the polymerase chain reaction in oesophageal and gastric carcinomas in Japan

M Saegusa, M Hashimura, Y Takano, M Ohbu, I Okayasu

\section{Short reports}

Novel method for detection of small amounts of RNA based on the semi-nested polymerase chain reaction $S$ Sanders, $G A$ Thomas

p53 gene mutations, and CYP1A1 and GSTM1 genotypes in pulmonary squamous cell carcinomas

S Ohshima, $Y X u$

\section{Miscellanea}

Book reviews 